doi: 10.47072/demiryolu.934471

Issue:14, Page: 65-76

http://dergipark.org.tr/demiryolu

e-ISSN: 2687-2463, ISSN: 2149-1607

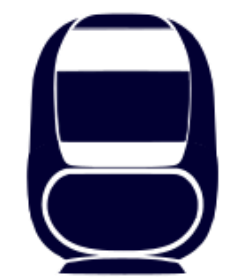

\title{
Tekerlek Ray Etkileşimi; Perlitik ve Beynitik Çeliklerin Yorulma Hasar Direnci Üzerine Bir Sonlu Elemanlar Analizi
}

\author{
Yasin SARIKAVAK (D) \\ Ankara Yıldırım Beyazıt Üniversitesi, Mühendislik ve Doğa Bilimleri Fakültesi, Makina Mühendisliği \\ Bölümü, Ankara, Türkiye \\ ysarikavak@ybu.edu.tr
}

(Alınış/Received: 07.05.2021, Kabul/Accepted: 05.06.2021, Yayımlama/Published: 31.07.2021)

Öz: Bu çalışmada ülkemizde ve dünyada demiryolu hatlarında işletme şartlarında çoğunlukla kullanımda olan perlitik mikroyapıdaki çelikler ve perlitik çeliklere alternatif olarak sunulan, gelişmiş mekanik özelliklere sahip olan beynitik mikroyapıdaki çelikler ele alınmıştır. Geniş bir literatür özetiyle konvansiyonel ray sınıfları ve gelişmiş ray sınıfları, kimyasal kompozisyonları ve temel mekanik özellikleri dikkate alınarak değerlendirilmiştir. Ayrıca dünyada farklı bölge ve ülkelerde geliştirilen beynitik ray çelikleri incelenmiş̧ir. Daha sonra tekerlek ray etkileşimi, sürtünme şartları ve temas yüzeyleri dikkate alınarak, geliştirilen sonlu elemanlar modelinde rayın yorulma hasar direnci analiz edilmiştir. Sonuç olarak analiz edilen beynitik mikroyapıdaki çeliğin yorulma hasar direncinin perlitik mikroyapıya göre üstün olduğu ve 386,69 MPa yük altında on milyon çevrime dayanabildiği anlaşılmıştır.

Anahtar kelimeler: Çelik yapılar, Demiryolu malzemeleri, Tekerlek-ray etkileşimi, Yorulma hasarı, Sonlu elemanlar analizi

\section{Wheel Rail Interaction; a Finite Element Analysis on Fatigue Failure Resistance of Pearlitic and Bainitic Steels}

\begin{abstract}
In this study, pearlitic microstructure steels, which are frequently used in the operational conditions of railways, and alternatively developed, bainitic microstructure steels, that has advanced mechanical properties are investigated. Conventional and advanced rail grades were investigated in terms of chemical composition and mechanical properties with an extended literature review. In addition, bainitic rail steels developed in different regions and countries were analyzed. Fatigue failure resistance of rails were analyzed with finite element method considering wheel-rail interaction, friction parameters and contact regions. In conclusion, analyzed bainitic microstructure shows advanced fatigue characteristics than pearlitic microstructure with ten million cycle resistance under $386.9 \mathrm{MPa}$ load.
\end{abstract}

Keywords: Steel structures, Railway materials, Wheel-rail interaction, Fatigue failure, Finite element analysis

\section{Giriş}

Dünyada demiryolu sistemlerindeki son gelişmeler, işletmedeki verimliliğin yanısıra güvenlik ve güvenilirliğin arttığı, ilk maliyetlerin ve işletme maliyetlerinin azaldığı yenilikçi tasarımların gerekliliğini ve önemini ortaya koymaktadır. Diğer altsistemlerin yanısıra tekerlek ray etkileşimi, temas yüzeyinin küçük bir alanda meydana gelmesi, güvenliği, konforu ve sağlamlığı etkileyen temel etkenlerden birisidir [1]. Artan hız, aks yükleri ve işletme frekanslarına bağlı olarak özellikle tekerlek ve ray temas yüzeylerinde hasarlar daha sıklıkla meydana gelmektedir.

Artan talepleri karşılamak üzere, ulaştırma sektöründeki gelişime bağlı olarak, özellikle demiryolu ulaştırmasında aşınma ve yorulma durumları daha sık olarak karşılaşılan işletme problemleri arasında yer almaktadır [2]. Ülkeler ve demiryolu işletmecileri emniyeti geliştirmek

Atıf için/Cite as: Y. Sarıkavak, "Tekerlek ray etkileşimi, perlitik ve beynitik çeliklerin yorulma hasar direnci üzerine bir sonlu elemanlar analizi," Demiryolu Mühendisliği, no 14, pp. 65-76, July. 2021. doi: 10.47072/demiryolu.934471 
ve sürekli hale getirmek için çaba sarf etmektedirler ve bunun sonucu olarak en güvenli ulaştırma modları arasında yer alan demiryollarında, kazaları en aza indirmeyi hedeflemektedirler [3]. Kazaların pek çoğunun temelinde, mekanik temas ve sürtünmeye bağlı olarak meydana gelen malzeme hasarları yer almaktadır. Aşınma ve yorulma durumları için tekerlek ray etkileşiminin doğru ve gerçekçi modellenmesi, ray ve tekerlek gibi malzemelerin çevrimsel yük altında lineer olmayan malzeme davranışlarının analiz edilmesi, işletme güvenliğini sağlamak açısından oldukça önemlidir.

Demiryollarında işletme hızlarının ve trafik yüklerinin artması, ray malzemelerinde de sürekli yenilik ve iyileştirme yapılması gerekliliğini ortaya koymuştur. Tarihsel gelişime bakıldığında kronolojik olarak standart perlitik raylar, yüksek aşınma dirençli raylar, mantarı sertleştirilmiş raylar ve beynitik raylar üzerine çalışmalar olduğu görülmektedir [4]. Tablo 1'de değişik sınıflardaki ray çeliklerinin mikroyapı, kimyasal kompozisyon, çekme mukavemeti, yüzde uzama ve sertlik değerleri yer almaktadır. Buna göre R260 kalite standart rayın çekme mukavemeti 880 MPa, sertliği 260-300 BHN (Brinel Sertlik Değeri - BHN); R350 HT mantarı sertleştirilmiş rayın çekme mukavemeti $1175 \mathrm{MPa}$, sertliği 350-390 $\mathrm{BHN}$; beynitik raylarda ise $1400 \mathrm{MPa}$ çekme mukavemeti, 430 BHN'dan büyük sertlik değerlerine erişilmiştir.

Tablo 1. Ray çelikleri ve malzeme özellikleri [4]

\begin{tabular}{|c|c|c|c|c|c|c|c|c|c|c|}
\hline \multirow{8}{*}{ 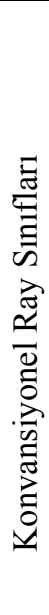 } & \multirow[t]{2}{*}{ Ray Sinıfi } & \multirow{2}{*}{$\begin{array}{c}\text { Isıl } \\
\text { İşlem }\end{array}$} & \multirow[t]{2}{*}{ Mikroyapı } & \multicolumn{4}{|c|}{ Kimyasal Kompozisyon } & \multirow{2}{*}{$\begin{array}{c}\mathrm{R}_{\mathrm{m}, \min } \\
\mathrm{MPa}\end{array}$} & \multirow{2}{*}{$\begin{array}{c}\text { Uzama } \\
\%\end{array}$} & \multirow{2}{*}{$\begin{array}{c}\text { Sertlik } \\
\text { HB }\end{array}$} \\
\hline & & & & $\mathrm{C}$ & $\mathrm{Si}$ & $\mathrm{Mn}$ & $\mathrm{Cr}$ & & & \\
\hline & R220 & & Perlit & $\begin{array}{c}0,50- \\
0,60\end{array}$ & $\begin{array}{c}0,20- \\
0,60\end{array}$ & $\begin{array}{c}1,00- \\
1,25\end{array}$ & $\leq 0,15$ & 770 & 12 & $\begin{array}{l}220- \\
260\end{array}$ \\
\hline & $\mathrm{R} 260$ & & Perlit & $\begin{array}{c}0,62- \\
0,80\end{array}$ & $\begin{array}{c}0,15- \\
0,58\end{array}$ & $\begin{array}{c}0,70- \\
1,20\end{array}$ & $\leq 0,15$ & 880 & 10 & $\begin{array}{l}260- \\
300\end{array}$ \\
\hline & $\mathrm{R} 260 \mathrm{Mn}$ & & Perlit & $\begin{array}{c}0,55- \\
0,75\end{array}$ & $\begin{array}{c}0,15- \\
0,60\end{array}$ & $\begin{array}{c}1,30- \\
1,70\end{array}$ & $\leq 0,15$ & 880 & 10 & $\begin{array}{l}260- \\
300\end{array}$ \\
\hline & $\mathrm{R} 320 \mathrm{Cr}$ & & Perlit & $\begin{array}{c}0,60- \\
0,80\end{array}$ & $\begin{array}{c}0,50- \\
1,10\end{array}$ & $\begin{array}{c}0,80- \\
1,20\end{array}$ & $\begin{array}{c}0,80- \\
1,20\end{array}$ & 1080 & 9 & $\begin{array}{l}320- \\
360\end{array}$ \\
\hline & R350HT & $\sqrt{ }$ & Perlit & $\begin{array}{c}0,72- \\
0,80\end{array}$ & $\begin{array}{c}0,15- \\
0,58\end{array}$ & $\begin{array}{c}0,70- \\
1,20\end{array}$ & $\leq 0,15$ & 1175 & 9 & $\begin{array}{l}350- \\
390\end{array}$ \\
\hline & R350LHT & $\sqrt{ }$ & Perlit & $\begin{array}{c}0,72- \\
0,80\end{array}$ & $\begin{array}{c}0,15- \\
0,58\end{array}$ & $\begin{array}{c}0,70- \\
1,20\end{array}$ & $\leq 0,30$ & 1175 & 9 & $\begin{array}{c}350- \\
390\end{array}$ \\
\hline & 370LHT & $\sqrt{ }$ & Perlit & $\begin{array}{c}0,70- \\
0,82\end{array}$ & $\begin{array}{c}0,40- \\
1,00\end{array}$ & $\begin{array}{c}0,70- \\
1,10\end{array}$ & $\begin{array}{c}0,40- \\
0,70\end{array}$ & 1175 & 9 & $>370$ \\
\hline$\underset{E}{E}$ & 380UHC & $\sqrt{ }$ & Perlit & $\begin{array}{c}0,90- \\
1,00\end{array}$ & $\begin{array}{c}0,20- \\
0,35\end{array}$ & $\begin{array}{c}1,20- \\
1,30\end{array}$ & $\begin{array}{c}0,25- \\
0,30\end{array}$ & 1200 & 9 & $>380$ \\
\hline $\begin{array}{l}\Xi \\
\text { क } \\
\vec{\Xi}\end{array}$ & 400UHC & $\sqrt{ }$ & Perlit & $\begin{array}{c}0,90- \\
1,00\end{array}$ & $\begin{array}{c}0,20- \\
0,35\end{array}$ & $\begin{array}{c}1,20- \\
1,30\end{array}$ & $\begin{array}{c}0,25- \\
0,30\end{array}$ & 1240 & 9 & $>380$ \\
\hline$\stackrel{\mathscr{c}}{\Xi}$ & $\begin{array}{c}\text { DOBAIN } \\
340\end{array}$ & $\sqrt{ }$ & Beynit & $\begin{array}{c}0,76- \\
0,84\end{array}$ & $\begin{array}{c}0,20- \\
0,35\end{array}$ & $\begin{array}{c}0,80- \\
0,90\end{array}$ & $\begin{array}{c}0,40- \\
0,55\end{array}$ & 1100 & 11 & $\begin{array}{c}340- \\
380\end{array}$ \\
\hline 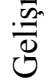 & $\begin{array}{c}\text { DOBAIN } \\
380\end{array}$ & $\sqrt{ }$ & Beynit & $\begin{array}{c}0,76- \\
0,84\end{array}$ & $\begin{array}{c}0,20- \\
0,35\end{array}$ & $\begin{array}{c}0,80- \\
0,90\end{array}$ & $\begin{array}{c}0,40- \\
0,55\end{array}$ & 1250 & 10 & $\begin{array}{c}380- \\
420\end{array}$ \\
\hline & $\begin{array}{c}\text { DOBAIN } \\
430\end{array}$ & $\sqrt{ }$ & Beynit & $\begin{array}{c}0,76- \\
0,84\end{array}$ & $\begin{array}{c}0,20- \\
0,35\end{array}$ & $\begin{array}{c}0,80- \\
0,90\end{array}$ & $\begin{array}{c}0,40- \\
0,55\end{array}$ & 1400 & 9 & $>430$ \\
\hline
\end{tabular}

Standart raylar perlitik mikroyapıdadır. Kaba taneli perlitik mikroyapı mekanik özelliklerinden dolayı tercih edilmiştir. Ancak yüksek hızda işletme frekanlarının artması ve dar yarıçaplı kurplarda ray üzerine gelen kuvvetlerin artmasıyla raylarda daha sık hasarlar gözlenmiş ve ince taneli perlit yapıya yönelim gerçekleşmiştir. Perlitik ray mantarına 1sıl işlem uygulanarak mantarı sertleştirilmiş raylar geliştirilmiş ve bu malzeme üretimleri uygulama alanı bulmuştur. Mantarı sertleştirilmiş raylar hadde sıcaklığından hızlı bir şekilde soğutularak tüm ray mantarı alanında optimum aşınma direncine sahip ince perlitik yapının oluşturulması ile elde edilir. İnce perlitik 
yapının mümkünse tüm mantarda elde edilmesi beklenir, ancak yüzeyden en az $20 \mathrm{~mm}$ ve üzerinde yapı derinliği olması da yeterlidir [5].

Yeni ray malzemesi geliştirmenin temel amacı, rayların mekanik ve aşınma özelliklerini iyileştirmek olmuştur. Bu hedefe ulaşmak için ray üreticileri çeliğin sertliğini artırmıştır. Fakat konvansiyonel perlitik ray çeliklerinde sertlik değeri belirli bir limite kadar erişebilmektedir. Sonuç olarak konvansiyonel perlitik ray çeliklerine göre daha yüksek sertlik değerlerine ulaşabilen alternatif mikroyapılı beynitik çelikler üzerine çalışmalara odaklanılmıştır. Beynitik çelikler yakın zamana kadar istenilen dayanım ve tokluk değerlerinde üretilememekteydi. Görece yeni uygulama alanı bulan bu çelikler, ilk yıllarda düşük karbonlu ve orta karbonlu beynitik çelikler olarak uygulanmaya başlandı. İlk olarak demiryollarında tüm makas bölgesini kapsayan ve uygulama alanı bulan beynitik mikroyapıdaki çeliklerin tüm hat boyunca kullanımına yönelik araştırma geliştirme ve saha deneme çalışmaları halen devam etmektedir. Bu kapsamda kimyasal kompozisyon ve 1sıl işlem rejimlerinin etkilerini inceleyen farklı çalışmalar literatürde yer almaktadır [6]. Amerika ve Japonya'da yer alan beynitik yapıdaki çelik kompozisyonları ve sertlik değerleri Tablo 2 ve Tablo 3'de yer almaktadır $[6,7]$.

Tablo 2. Japonya'da geliştirilen ve test edilen beynitik mikroyapıdaki ray çelikleri özellikleri [7]

\begin{tabular}{|c|c|c|c|c|c|c|c|c|c|c|c|}
\hline Çelik & $\mathrm{C}$ & $\mathrm{Si}$ & $\mathrm{Mn}$ & $\mathrm{P}$ & $\mathrm{S}$ & $\mathrm{Cr}$ & $\mathrm{V}$ & Mo & $\mathrm{Nb}$ & B & $\begin{array}{c}\text { Sertlik } \\
{[\mathrm{HB}]}\end{array}$ \\
\hline A & 0,28 & 0,3 & 1,21 & 0,013 & 0,009 & 1,65 & 0,1 & & & & 399 \\
\hline B & 0,31 & 0,31 & 1,32 & 0,013 & 0,008 & 1,32 & & 0,26 & & & 354 \\
\hline $\mathrm{C}$ & 0,29 & 0,55 & 1,10 & 0,01 & 0,006 & 2,21 & & & 0,04 & & 375 \\
\hline D & 0,34 & 0,32 & 0,70 & 0,011 & 0,007 & 2,51 & & & & 0,0015 & 388 \\
\hline
\end{tabular}

Tablo 3. Amerika'da geliştirilen ve test edilen beynitik mikroyapıdaki ray çelikleri [7]

\begin{tabular}{lllllllll}
\hline Çelik & $\mathrm{C}$ & $\mathrm{Mn}$ & $\mathrm{Si}$ & $\mathrm{Cr}$ & $\mathrm{Mo}$ & $\mathrm{Ni}$ & $\mathrm{B}$ & $\begin{array}{l}\text { Sertlik } \\
{[\mathrm{HB}]}\end{array}$ \\
\hline J1 & 0,181 & 2,01 & 1,13 & 1,94 & 0,48 & 0,01 & 0,003 & 415 \\
J2 & 0,115 & 3,97 & 0,27 & 0,02 & 0,47 & 0,01 & 0,003 & 375 \\
J3 & 0,077 & 2,03 & 0,27 & 1,97 & - & 1,93 & - & 363 \\
J4 & 0,023 & 2,02 & 0,27 & 1,96 & 0,48 & 1,93 & 0,003 & 271 \\
J5 & 0,026 & 4,04 & 0,27 & 0,02 & - & 0,02 & - & 288 \\
J6 & 0,258 & 2,00 & 1,81 & 1,93 & 0,49 & 0,00 & 0,003 & 490 \\
\hline
\end{tabular}

Lee ve Polcarpou [8] orta karbonlu perlitik ve beynitik ray çeliklerinin aşınma davranışını incelemiştir. Bu çalışmada beynitik ve perlitik ray numuneleri hat üzerinde denenmiş daha sonrasında ise aşınma özellikleri laboratuvar ortamında incelemişlerdir. Sonuç olarak beynitik J6 çeliklerin perlitik çeliklere göre daha fazla aşındığı görülmüştür. Bir diğer çalışmada ise düşük karbonlu beynitik çeliklerde karbürsüz beynitik mikroyapının artmasıyla aşınma direncinin arttığı tespit edilmiştir. Karbürsüz beynit mikroyapının oluşumu için karbon içeriğinin ve soğutma oranının artırılması gerekliliği ifade edilmiştir [9]. Hasan vd. [10] düşük karbonlu, devamlı soğutulmuş, karbürsüz yeni geliştirilmiş beynitik ray çelikleri ve perlitik ray çeliklerinin haddeleme ve kayma aşınma davranışlarını incelemişlerdir. Beynitik ray çelikleri perlitik ray çeliklerine göre yüksek aşınma direnci göstermiştir. Sertlik değerinin artmasının aşınma direncinde artışa neden olduğu sonucuna varılmıştır. Karbürsüz beynitik ray çeliklerinin detaylı mikroyapı analizleri yapılmış, kalıntı östenit miktarının artması ve beynitik ferrit kafes kalınlığının düşmesiyle aşınma direncinin arttığı gözlenmiştir.

Morton vd. [11] raylardaki hasarları ve çevresel etkileri azaltmak için önerilen yeni ray malzemelerinin dikkatli ve detaylı şekilde analiz edilmesi gerektiğini ifade etmiş̧lerdir. Malzeme davranışlarını incelemek için İngiliz Demiryolları işletme şartlarını laboratuvar ortamında simüle edip, malzeme kimyasal yapısı etkisi, hasar oluşumu ve mekanik özellikler konusunda çeşitli 
sonuçlara varmıştır. Daha sonraki yıllarda ise beynitik çelikler üzerindeki araştırmalar artmıştır. İmalat, kimyasal kompozisyon ve 1 sıl işlem parametreleri dikkate alınarak performansın artması sağlanmış ve son yıllarda beynitik çeliklerin inşaat yapılarında, boru hatlarında, otomotiv uygulamalarında, demiryolu ray ve makaslarında uygulaması gündeme gelmiştir. Beynit geniş aralıktaki sıcaklıklarda ve farklı morfolojilerde oluşturulabilmekte, içeriğindeki alaşım elementleri ve uygulanan 1 sıl işlem rejimleri mekanik değerlerini önemli ölçüde etkilemektedir.

Viafara vd. [12] perlitik ve beynitik çeliklerin yağsı kayma aşınma davranışlarını incelemişlerdir. 10,30 ve $50 \mathrm{~N}$ yükler altında tüm testlerde kayma hızı $1 \mathrm{~ms}^{-1}$ olarak uygulanmıştır. Aşınma direnci kütle kaybıyla orantılı olarak hesaplanmıştır. Perlitik çelikler, beynitik çeliklere göre yüksek kayma aşınma direnci göstermiştir. Chang [13] yüksek silikon içerikli, karbürsüz, farklı mikroyapı karakteristikleri gösteren beynitik rayların aşınma davranışlarını incelemiş̧ir. Sonuç olarak sert malzemelerin düşük aşınma oranına sahip olduğu ve mikroyapıdaki kalıntı ferrit gibi bileşenlerin aşınma performansına negatif yönde etki ettiğ $i$ anlaşılmıştır. Singh ve arkadaşları [14] daha uzun işletme ömürlerine dayanması nedeniyle beynitik ray çeliklerinin potansiyel olarak ötektoid ray çelikleri yerine geçeceğini belirtmiştir. Bu kapsamda beynitik ray çelikleri üretilmiş ve ferritik çeliklerle charpy darbe direnci ve dayanım limitleri karşılaştırılmıştır. Üretilen beynitik çeliklerin 1100-1350 MPa aralığında değişen çekme mukavemeti olduğu tespit edilmiş ve charpy $\mathrm{v}$ çentik darbe dayanımının perlitik çeliklere göre yüksek olduğu sonucuna varılmıştır. Buna göre perlitik çeliklerde 8-10 J mertebesinde olan darbe dayanımının, beynitik çeliklerde 14-19 J mertebelerinde olduğu raporlanmıştır.

Yokoyama vd. [15] yüksek tonajlı demiryollarında kullanılmak üzere yüksek pullanma direncine sahip yüksek dayanımlı beynitik ray çeliklerini geliştirmişlerdir. Bu çalışmada farklı çekme dayanımına sahip perlitik ve beynitik ray çeliklerinin yuvarlanma temas yorulması ve aşınma davranışları incelenmiştir. Beynitik ve perlitik çeliklerde beyaz dağlama katmanının (white etching layer) oluşum davranışı incelenmiş ve bunun pullanma direncine etkisi araştırılmıştır. Yeni geliştirilen yüksek dayanımlı beynitik çeliklerin yüksek pullanma direnci, iyi aşınma direnci ve mükemmel kaynaklanabilirlik özelliklerine sahip olduğu anlaşılmıştır.

Aglan vd. [16] beynitik ray çeliklerinin mekanik ve kırılma davranışlarını incelemişlerdir. Deneyler sonucunda perlitik ray çeliğine göre en yüksek çekme mukavemetinde \%36, akma mukavemetinde ise \%77 iyileşme olduğu görülmüştür. Gui vd. [17] beynitik ray çeliklerinin de mikroyapının yuvarlanma temas yorulması (RCF) üzerine etkisini incelemiştir. Isıl işlem sonucu iki farklı mikroyapıya (B380 ve B340) sahip beynitik ray çelikleri imal edilmiştir. İmal edilen çelikler, demiryolu yük hattı üzerine monte edilerek saha testleri yapılmış bunun yanısıra laboratuvar testleri yapılmıştır. İki farklı 1sıl işlem sonucu elde edilen B380 ve B340 beynitik ray çeliklerinin çekme dayanımı 1406 ve 1417 MPa olarak tespit edilmiştir. Kalıntı östenitin RCF'de çatlak ilerlemesi üzerinde önemli etkisi olduğu sonucuna varılmıştır. Hlavaty vd. [18] dünya çapında demiryolundaki gelişmelere paralel olarak yüksek mukavemet ve aşınma direnci nedeniyle özellikle ray çeliklerinde beynitik mikroyapının demiryolu uygulamalarındaki önemi üzerinde durmuşlardır. Yüksek hızlı tren hatlarında ray hasarını en aza indirmek [19], rayların aşınma değerleri ve yuvarlanma temas yorulmasında iyileştirmeler için yeni beynitik rayların geliştirilmesi konularında çalışmalar yapılmıştır [20].

Ülkemizin gelecek hedefleri doğrultusunda, $10000 \mathrm{~km}$ yeni yüksek hızlı tren hattı döşenmesi planlanmaktadır [21]. Bu hatların bir kısmı projelendirilmiş, bir kısmı inşaat aşamasında ve diğer bir kısmı da yakın zaman içerisinde işletmeye alınacaktır. Bu hedef doğrultusunda ray hasarlarının ve bakım periyotlarının düşürülmesi açısından beynitik rayların değerlendirilmesi kritik önem taşımaktadır. Li vd. [22] çalışmalarında demiryolu makaslarında kullanılan beynitik ray çeliklerinde imalat esnasında oluşan yüksek yoğunluktaki dislokasyonların ve martensitin mekanik özelliklerde farklılaşmaya neden olduğunu belirlemişlerdir. Düşük hızdaki gerinim testleri sonucunda hasarlı beynitik çeliklerin hidrojen gevrekleşmesine karşı hasarsız beynitik 
çeliklere göre daha hasas olduğu kanaatine varılmıştır. Zhang vd. [23] hidrojenin beynitik çelik makaslara etkisini incelemiştir. Hidrojen miktarının artması kesit alan daralması (boyun oluşumu) ve uzama gibi plastisite özelliklerinin keskin şekilde düşmesine neden olmaktadır.

Haddad vd. [24] yüksek mukavemetli nano kristal beynitik çeliklerin çekme testi üzerine çalışmışlardır. Konvansiyonel metodlara göre yenilikçi imal metodları ile nano kristalli yüksek dayanımlı malzemeler üretilmektedir. Bu çalışmada $\mathrm{C} 45$ tipi ticari $(\mathrm{Fe}, 0.42-0,5 \mathrm{wt} \% \mathrm{C}, 0,5-$ $0,8 \mathrm{wt} \% \mathrm{Mn}$ ) içerikli orjinal mikroyapısı ferritik-perlitik olan çelik, beynite dönüştürülmüştür. İlk durumda $800 \mathrm{MPa}$ çekme dayanımı ve \%16 toplam uzama değerleri, nano ölçekli beynit ile 2100 MPa çekme dayanımı ve \%4,5 toplam uzama değerine iyileşmiştir. Yüzeyde oluşan süreksizlikte gerilim birikmesi sonucu herhangi bir boyun oluşumu olmadan ani kırılma gerçekleşmiştir. Clayton vd. [25] beynitik raylarda aşınma oranını kimyasal kompozisyon, sertlik, yorulma özellikleri, çekme dayanımı, charpy darbe dayanımı ve mikroyapı parametrelerini dikkate alarak analiz etmiştir. Szablewski vd. [26] ağır yük taşımacılığında yüksek performanslı çeliklerin geliştirilmesi üzerine çalışmıştır. Bu çalışmada elde edilen sonuçlar, demiryollarında karar verme sürecinde optimum çelik türünün seçilmesine katkı sağlamıştır. Amerika'da bulunan Ulaştırma Teknoloji Merkezi (TTCI) yirmi yıldan uzun süredir yüksek aks yüklerinde üstün çeliklerin geliştirilmesi konusunda çalışmaktadır. Aks yüklerinin artması raylara gelen darbe yüklerinin tam ölçekli sistemlerle araştırılması gerekliliğini ortaya çıkarmışırı. TTCI aralarında ABD, Japonya, Çin, Fransa, Avusturya, İspanya ve İtalya'nın bulunduğu dünyanın önde gelen ray üreticilerinden temin ettiği rayları, tam ölçekli konrollü çevre kosullarına sahip test yolunda denemiş ve değerlendirmiştir. Testler sertliğe bağlı aşınma ve yorulma davranışlarının incelenmesiyle başlamıştır. Yedi farklı imalatçıya ait on farklı ray sınıfı testlere tabi tutulmuştur.

$\mathrm{Bu}$ çalışmada ülkemizde konvansiyonel ve yüksek hızlı tren hatlarında kullanılan perlitik mikroyapıdaki raylar ve dünyada geliştirilen beynitik mikroyapıdaki rayların performansları sonlu elemanlar yöntemi kullanılarak analiz edilmiştir. Dünyada demiryolu literatüründe kullanımda olan ve potansiyel olarak kullanılabilecek, Ar-Ge ve saha deneme koşullarında analiz edilen çeliklerin ve konvansiyonel çeliklerin çevrimsel yük altında dayanımı, tekerlek ray etkileşimi dikkate alınarak incelenmiştir.

\section{Metot}

\subsection{Kullanilan malzemeler}

$\mathrm{Bu}$ çalışmada ray ve tekerlek çeliklerinin montajı ile arayüz teması sonucu oluşan yorulma performansı incelenmiştir. Türkiye Cumhuriyeti Devlet Demiryolları (TCDD) bünyesinde yer alan ve işletme altındaki konvansiyonel ve yüksek hızlı tren hatlarında ağırlıklı olarak kullanılan tekerlek ve ray profili analiz edilmiştir [27]. Rayın ölçüleri ve ray mantarında tekerlek ile etkileşim halinde olan yuvarlanma yüzeyleri Şekil 1'de yer almaktadır. Buna göre ray mantarında 300, 80 ve $13 \mathrm{~mm}$ ölçülerinde üç yarıçap yer almaktadır ve bu bölgeler sırasıyla taç (crown), omuz (shoulder) ve köşe (gauge corner) olarak adlandırılmıştır. Tekerleğin enine yönde hareketine bağlı olarak, ilk temas yüzeyi bu üç konumda yer alabilmektedir. Tren işletme frekanslarına bağlı olarak, tren geçişlerinde aşınma ve plastik deformasyon sonucu belirtilen ölçülerde değişiklikler olabilmektedir.

EN ISO 13674-1 (UIC 60 R260)'e göre, perlitik mikroyapıdaki rayın çekme mukavemeti \%10 uzamayla en az $880 \mathrm{MPa}$ olmalıdır [28]. Buna göre sonlu elemanlar analizi için çekme dayanımı 909,6 MPa ve akma dayanımı 460,3 MPa; yogunluğu $7850 \mathrm{~kg} / \mathrm{m}^{3}$, elastisite modülü $210 \mathrm{GPa}$ ve poisson oranı 0,3 olarak alınmış ve hesaplamalarda kullanılmıştır [29, 30]. Tekerlek çapı 850 mm'dir [27]. Çekme ve akma dayanımı sirasıyla $900 \mathrm{MPa}$ ve $580 \mathrm{MPa}$ olarak analizlerde kullanılmıştır [31]. Elastisite modülü, poisson oranı ve yoğunluğu sırasıyla $210.000 \mathrm{MPa}, 0,3 \mathrm{ve}$ $7850 \mathrm{~kg} / \mathrm{m}^{3}$ 'dir [32]. Dünyada farklı özelliklerde beynitik mikroyapıda çelik geliştirilmiştir. Bu 
çalışmada J1 tip beynitik çelikler sonlu elemanlar analiz çalışması için kullanılmıştır. Kullanılan beynitik mikroyapıdaki çelikler $1360 \mathrm{MPa}$ çekme mukavemetine, $846 \mathrm{MPa}$ akma dayanımına ve $\% 14$ uzama değerine sahiptir $[16,33]$.

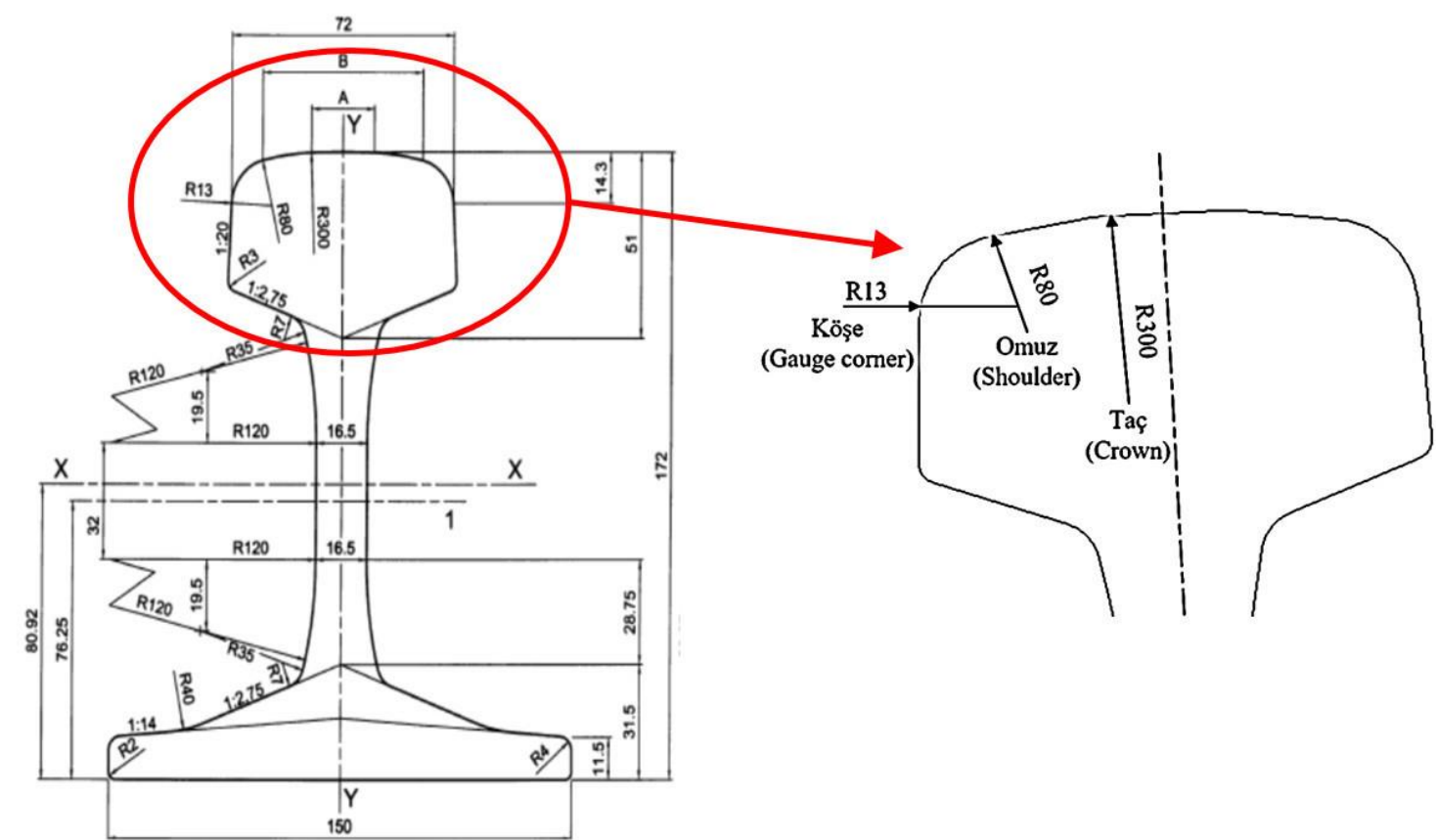

Şekil 1. UIC 60 E1 Profil ray ölçüleri ve ray mantar yüzeyindeki yer alan üç konum (köşe, omuz, taç) için dairesel yaylar

\subsection{Tekerlek ray teması ve modelleme}

Tekerlek ray yuvarlanma teması denge durumunda teorik olarak Hertz temas teorisiyle açıklanmaktadır ve elastik deformasyona bağlı olarak temas geometrisi ve gerilim değerleri gibi parametreleri incelemektedir [34, 35]. Buna göre iki elastik malzeme birbirlerine bask1 uyguladığında temas alanı eliptik bir şekil oluşturmaktadır ve bu eliptik şeklin ana ekseni 'a' ve tali ekseni ' $b$ ' olan iki farklı eliptik uzunluk ve derinlik meydana gelmektedir. Tekerlek ve ray arasındaki temas yüzeyi ve oluşan eliptik geometri Şekil 2'de yer almaktadır. Analizde, tekerlek ray temas bölgesinde deformasyon ve aşınmaya olanak sağlayacak sürtünmeli temas tanımlanmıştır ve sürtünme katsayısı 0,3 olarak tanımlanmıştır [36]. Tekerlek ray arayüzünde uygulanan yükün yirmi altbasamakla kademeli olarak raya iletilmesini sağlanmıştır. Tekerleğin enine yönde hareketine bağlı olarak, ilk temas ray mantarında 300,80 ve $13 \mathrm{~mm}$ ölçülerinde, sırasıyla taç (crown), omuz (shoulder) ve köşe (gauge corner) olarak adlandırılan üç yarıçap yüzeyinde yer alabilmektedir. Şekil 3'de tekerlek ray temas başlangıç konumları yer almaktadır. Bu çalışmada düz yolda gözlemlenen temas olan taç bölgesi teması analiz edilmiştir. 


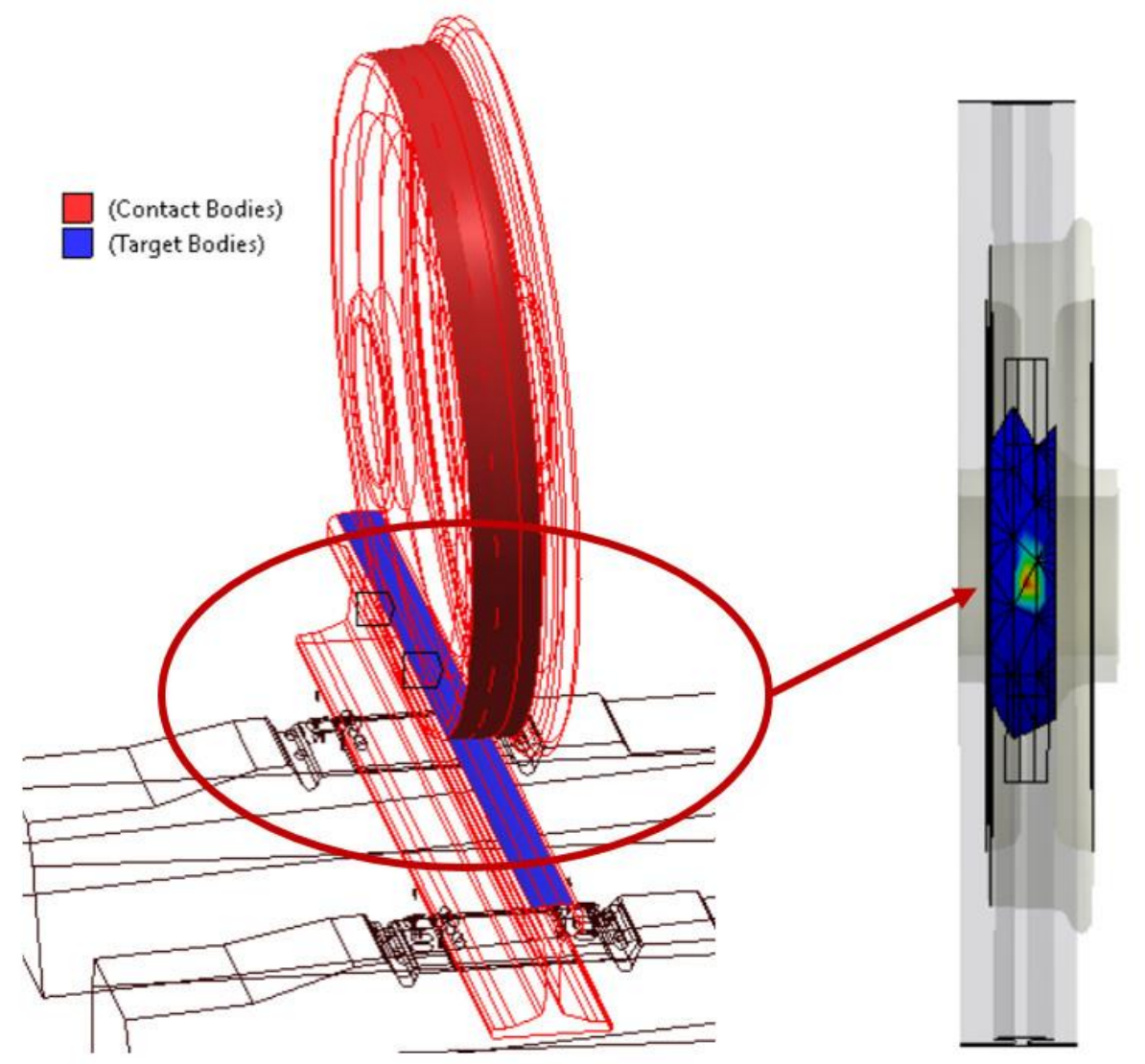

Şekil 2. Tekerlek ray kontak yüzeyleri
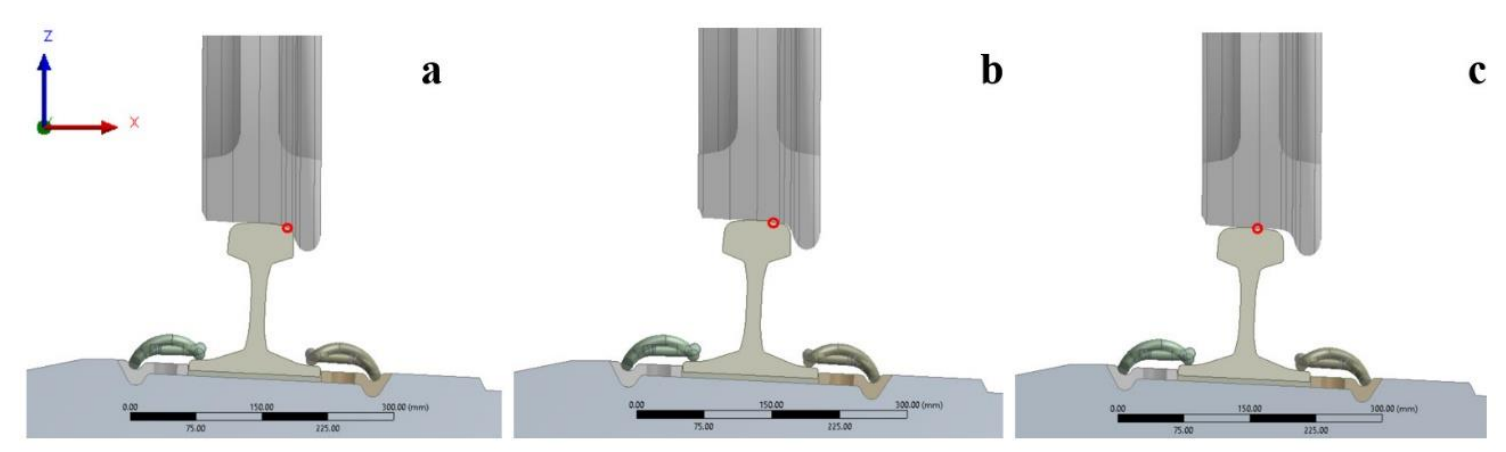

○ İlk kontak noktası

Şekil 3. Tekerlek ray temas başlangıç konumları a) İlk kontak köşe noktası (gauge corner) b) İlk kontak omuz noktası (shoulder) c) İlk kontak taç noktası (crown)

\subsection{Sonlu elemanlar analizi}

Sonlu elemanlar ile analiz (SEA) yöntemi lineer davranış gösteren ve göstermeyen malzemelerin modellemesinde çoğunlukla kullanılan bir yöntemdir. Yüksek hızlı tren hatlarında boji tipi dikkate alındığında rayla ve üstyapıyla temas halinde olan ve aksla tekerleğe aktarılan en yüksek statik yük değeri 70,49 kN'dur. Türkiye Cumhuriyeti Devlet Demiryolları (TCDD) bünyesinde traversler arası açıklık $60 \mathrm{~cm}$ olup aks yükü 22,5 ton/aks olarak tasarlanmıştır [37]. Demiryolu altyap1 ve üstyap1 sisteminde boyuna düzlemde simetri olduğu için sonlu elemanlar analizi çalışmasında analiz sürelerini kısaltmak için yarım model kullanılmıştır. Tekerlek ve ray teması olan bölgede (rayın ve tekerleğin yuvarlanma yüzeyi) ağ eleman sayıları analiz hassasiyetini artırmak için artırılmış, diğer bölgeler de ise ağ eleman sayıları düşük tutularak analiz süresinin 
kısaltılması sağlanmıştır. Bu kapsamda altıyüzlü ve dörtyüzlü ağdan oluşan sonlu elemanlar modeli 76630 düğüm ve 26160 elemandan oluşmaktadır. Sonlu elemanlar modelinde tekerlek bileşenine, aks yuvasında, $-\mathrm{z}$ ekseninde aks yükü tanımlanmıştır. Bunun yanısıra tekerlek, ray, travers ve diğer bileşenlerin yüke bağll $-\mathrm{z}$ ekseninde hareketine olanak sağlanmış ancak $-\mathrm{y}$ ekseninde hareketi sınırlandırılmıştır. Dolayısıyla gerçek işletme şartlarında dikey eksende uygulanan yük ve sistemin bu yüke tepkisi işletme şartları dikkate alınarak modelde tanımlanabilmiştir. Yorulma hasar analizi için gerilim-ömür, gerinim-ömür ve benzeri diğer analiz metodları araştırmacılar tarafından kullanılmaktadır. Bu çalışmada ortalama gerilmelerin etkisi ve ömür analizi için gerilim-ömür tabanlı hesaplama yapan Şekil 4'de yer alan Goodman eşitliği, Denklem 1 kullanılmıştır.

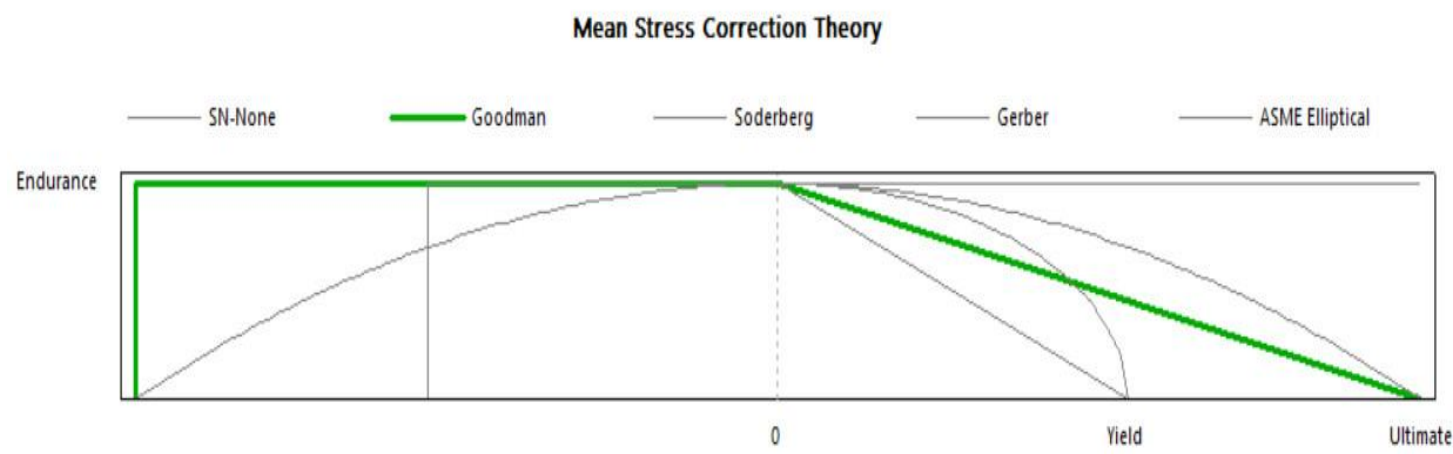

Şekil 4. Analizde kullanılan ortalama gerilme değeri Goodman diyagramı

$$
\frac{\sigma_{m}}{\sigma_{u}}+\frac{\sigma_{a}}{\sigma_{e}}=\frac{1}{n}
$$

Burada, en yüksek çekme gerilme değerini temel alan Goodman eşitliğinde; $\sigma_{\mathrm{m}}$ ortalama gerilme, $\sigma_{a}$ gerilme genliği, $\sigma_{u}$ çekme mukavemeti, $\sigma_{\mathrm{e}}$ yorulma limit değeri ve $\mathrm{n}$ ise güvenlik faktörüdür.

\section{Bulgular}

Bu çalışmada ray mantarında düz yol şartlarında taç (crown) olarak tabir edilen $300 \mathrm{~mm}$ yarıçap boyunca tekerlek ve ray etkileşiminin olduğu durum analiz edilmiştir. Literatürde saha şartlarında tekerlek ray etkileşimi ile oluşan sonuçları analiz eden farklı çalışmalar yer almaktadır. $\mathrm{Bu}$ çalışmalar doğrudan yük değerini ölçebilmekte, yerdeğiştirme ve titreşim değerlerini ölçen farklı içerikteki çalışmalar da literatürde yer almaktadır. Bu kapsamda yapılan çalışmalarda yüksek hız altında ray ve diğer üstyapı malzemelerinin yerdeğiştirme değerleri gerçek işletme şartları altında ölçülmüştür [38]. Buna göre perlitik mikroyapıdaki ray malzemesinin yerdeğiştirme değeri, 66 $\mathrm{kN}$ tekerlek yükü altında $0,24 \mathrm{~mm}$ olarak ölçülmüştür. Aynı sınır şartları oluşturulan modelde kullanıldığında $0,33 \mathrm{~mm}$ yerdeğiş̧irme değeri analiz edilmiş ve geliştirilen modelin yeterli hassasiyette sonuçlar verdiği değerlendirilmiştir.

Şekil 5'de beynitik ve perlitik mikroyapıdaki çeliklerin, tanımlanan sınır şartları altında yüke bağlı dayanabildiği ömür grafiği yarı logaritmik ölçekte yer almaktadır. Buna göre beynitik çelik $531,3 \mathrm{MPa}$ yük altında 321780 çevrimsel yüke; $500 \mathrm{MPa}$ yük altında 773580 çevrimsel yük tekrarına; $451 \mathrm{MPa}$ yük altında 2454500 çevrimsel yük tekrarına; 418,84 MPa yük altında 5363500 çevrimsel yük tekrarına dayanabilmektedir. Kritik yük olan 386,69 MPa değerinde sonsuz ömür olarak tabir edebileceğimiz on milyon çevrim sayısına eriştiği grafikten anlaşılmaktadır. 
Perlitik mikroyapıdaki çelikler ise $275 \mathrm{MPa}$ yük altında 70736 çevrimsel yüke; 256,38 MPa yük altında 92705 çevrimsel yüke; $237,77 \mathrm{MPa}$ yük altında 419880 çevrimsel yüke; $228,45 \mathrm{MPa}$ yük altında 2483500 çevrimsel yüke dayanabilmektedir. Perlitik çelikler için kritik değer 219,15 MPa olarak hesaplanmıştır ve bu yük altında on milyon tekrara eriştiği Şekil 5'deki grafikten anlaşılmaktadır.

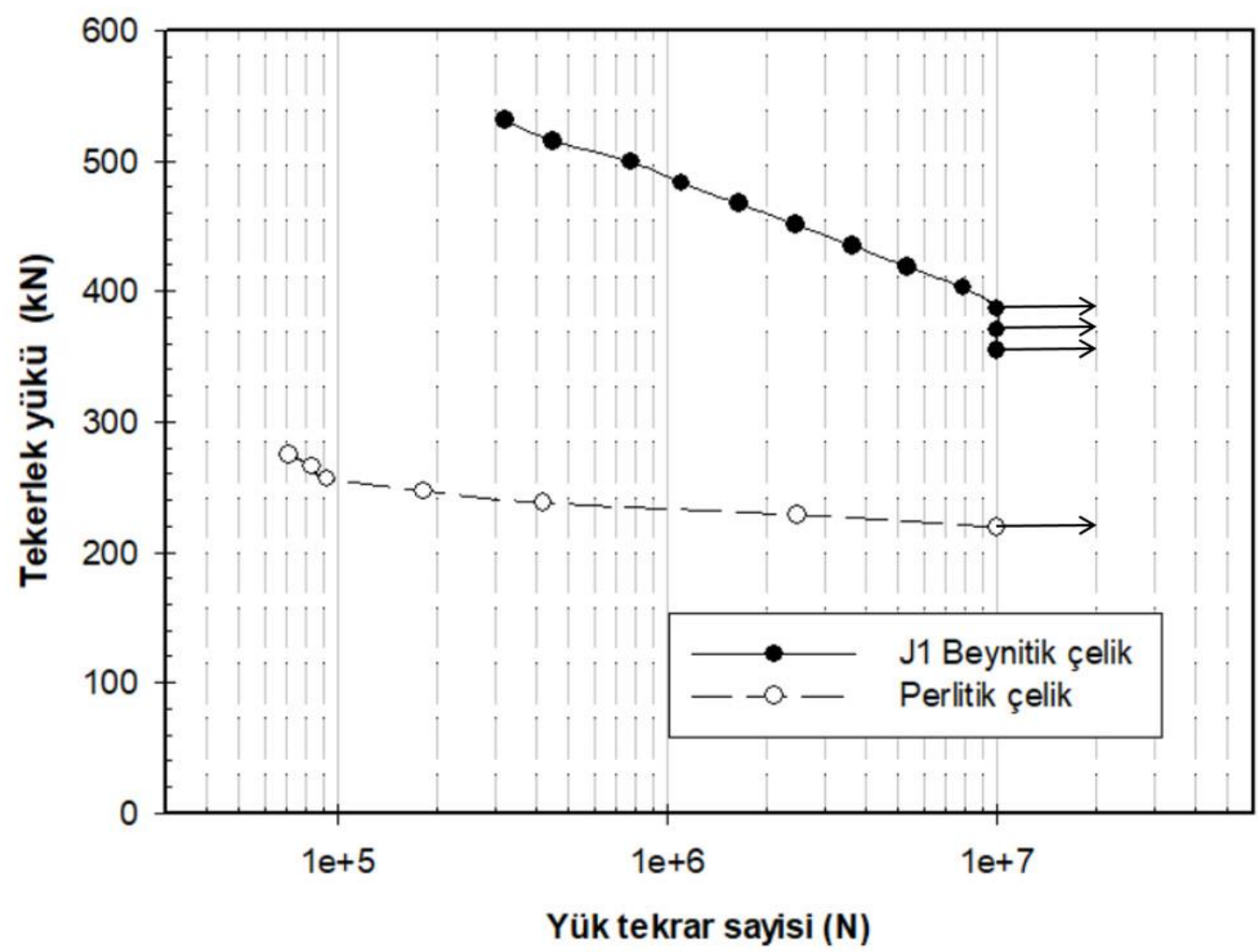

Şekil 5. Beynitik ve perlitik çelikler için yapılan analiz sonucu elde edilen çevrim sayısı ve yük grafiği

Beklenildiği gibi düşey yönde uygulanan yükün artmasıyla yorulma kaynaklı hasar direnci düşmekte, yorulma hasarı artmakta ve yük tekrar sayısı azalmaktadır. Bu durum hem perlitik mikroyapıdaki çelikler hem de beynitik mikroyapıdaki çelikler için geçerlidir. Beynitik çeliklerde kritik yük olan 386,69 MPa ve perlitik çeliklerde ise 219,15 MPa yük altında rayın on milyon çevrime dayanabildiği anlaşılmıştır. Kritik değer olan on milyon yük tekrar sayısında, beynitik çeliklerin dayanabildiği yük değerinin yüksek olduğu ve bu çeliklerin daha mukavim olduğu değerlendirilmektedir. Elde edilen sonuçlar dikkate alındığında perlitik çelikler için kritik değer olan 219,65 MPa yük değerinin üzerinde bir yükleme yapıldığında çevrim sayısı değerinde hızlı bir düşüşün meydana geldiği anlaşılmıştır.

Yapılan analiz sonucu beynitik çeliklerin çevrimsel yük altında dayanımının fazla olduğu, on milyon çevrime dayanan kritik yük olan 386,69 MPa değerini üzerine çıkıldığında dayanımın (çevrim sayısı) kademeli olarak azaldığı ve yük tekrar sayısı değerinde ani bir düşüşün olmadığ 1 incelenmiştir. Bu nedenle beynitik çeliklerde yüke bağlı gözlemlenen sürtünme ve aşınma sonucu oluşması muhtemel yüzey süreksizliklerinin daha uzun süreler sonrasında gözlemlenmesi beklenmektedir. $\mathrm{Bu}$ durum özellikle demiryolu işletmeciliğinde önemli bir parametre olan tahribatsız muayene periyotlarının da artmasına ve bakım temelli oluşacak maliyetlerin düşmesine sebep olacaktır. 


\section{Sonuç}

Bu çalışmada, ülkemizde ve dünyada demiryolu hatlarında çoğunlukla kullanımda olan perlitik mikroyapıdaki çelikler ve bu perlitik çeliklere alternatif olarak sunulan çeşitli patentlerin alındığ ve gelişmiş mekanik özelliklere sahip olan beynitik mikroyapıdaki çelikler ele alınmıştır. Geniş bir literatür özetiyle konvansiyonel ray sınıfları (perlitik mikroyapı) ve gelişmiş ray sınıfları (1sıl işlem görmüş, mantarı sertleştirilmiş perlitik mikroyapı ve beynitik mikroyapı) kimyasal kompozisyonları ve temel mekanik özellikleri dikkate alınarak değerlendirilmiştir. Ayrıca Japonya ve Amerika'da geliştirilen beynitik ray çeliklerinin kimyasal kompozisyonları ve mekanik özellikleri değerlendirilmiştir. Literatürde beynitik çeliklerle ilgili yapılan çalışmalar ve elde edilen sonuçlar kapsamlı olarak ele alınmıştır.

Tekerlek ray etkişimi yıllardır çalışılan ve günümüzde de çalışılmaya devam eden bir konudur. Modellenmesi oldukça karmaşık olan bu fiziksel durum ve temas koşulları bu çalışmada ele alınmıştır. Tekerlek ray temas bölgesinde deformasyon ve aşınmaya olanak sağlayacak sürtünmeli temas ve bu temas sonucu ray mantarının yuvarlanma yüzeyinde oluşan eliptik kontak geometrisi dikkate alınarak, yorulma hasar direnci için gerilim-ömür tabanlı hesaplama yapan Goodman eşitliği kullanılmıştır. Yapılan çalışmada, tekerlek ray temas yüzeyinde tanımlanan düğüm ve eleman sayılarının çözüme doğrudan ve önemli ölçüde etki ettiği anlaşılmıştır. Bu nedenle temas yüzeylerinde daha hassas elemanlar tanımlanarak analizler yapılmıştır. Analiz sonucunda, beynitik çeliklerde kritik yük 386,69 MPa ve perlitik çeliklerde ise 219,15 MPa olarak elde dilmiş ve bu yükler altında rayın on milyon çevrime dayanabildiği anlaşılmıştır. Buradan işletmecilikte güvenlik, sürdürülebilirlik ve maliyet açısından oldukça önemli olan bakım periyotlarının planlanması noktasında çeşitli sonuçlara varmak mümkündür. Bu kapsamda daha mukavim olan beynitik çeliklerde, yorulmaya bağlı hasar için çevrim sayısının yüksek olduğu; tekerlek veya rayda muhtemel aşırı yüklemeler sonucu (apleti ve ray kusurlarına bağlı oluşan darbe yükleri) dayanımın daha fazla olacağı ve bu durum özellikle görsel muayene, manyetik parçacıkla muayene ve ultrasonik muayene gibi tahribatsız muayene metodlarının uygulama periyotlarının artması ile bakım maliyetlerinde düşüşlere sebebiyet verebilecektir. Bundan sonra perlitik ve beynitik mikroyapıdaki çeliklerin üretilerek laboratuar şartlarında sürtünme ve aşınma karateristiklerinin belirlenmesi, ardından saha şartlarında sonuçların analiz edilerek gelişmiş ray sınıflarının ülkemizde de kullanımı konusunda çalışmaların artması sürdürülebilir işletmecilik açısından önem arz etmektedir.

\section{Kaynakça}

[1] H. Tehrani and M. Saket, "Fatigue crack initiation life prediction of railroad," in 7th International Conference on Modern Practice in Stress and Vibration Analysis, 2009, pp. 1-8.

[2] R. Masoudi Nejad, K. Farhangdoost, and M. Shariati, "Microstructural analysis and fatigue fracture behavior of rail steel," Mech. Adv. Mater. Struct., vol. 27, no. 2, pp. 152-164, 2018, doi: 10.1080/15376494.2018.1472339.

[3] O. Akbayır, "Dünya'da ve Türkiye'de demiryolu kazaları nedeniyle meydana gelen ölüm oranlarının karşılaştırılması," Demiryolu Mühendisliği, vol. 5, pp. 45-52, 2017.

[4] R. Heyder and G. Girsch, "Advanced pearlitic and bainitic high strength rails promise to improve rolling contact fatigue resistance," in 7th World Congress on Railway Research, 2006, no. August, p. 234.

[5] A. Moser and P. Pointner, "Head-hardened rails produced from rolling heat," Transp. Res. Rec., no. 1341, pp. 70-74, 1992.

[6] K. F. Rodriguez-galeano, R. Rodriguez-baracaldo, A. Mestra-rodriguez, J. M. Cabrera-marrero, and J. J. Olaya-florez, "Influence of boron content on the fracture toughness and fatigue crack propagation kinetics of bainitic steels," Theor. Appl. Fract. Mech., vol. 86, pp. 351-360, 2016, doi: 10.1016/j.tafmec.2016.09.010.

[7] I. Hlavaty, M. Sigmund, L. Krejci, and P. Mohyla, "The Bainitic steels for rails applications," Mater. Eng., vol. 16, no. 4, pp. 44-50, 2009, [Online]. Available: 
[8] K. M. Lee and A. A. Polycarpou, "Wear of conventional pearlitic and improved bainitic rail steels," Wear, vol. 259, no. 1-6, pp. 391-399, 2005, doi: 10.1016/j.wear.2005.02.058.

[9] N. Jin and P. Clayton, "Effect of microstructure on rolling/sliding wear of low carbon bainitic steels," Wear, vol. 202, pp. 202-207, 1997.

[10] S. Hasan, D. Chakrabarti, and S. B. Singh, "Dry rolling / sliding wear behaviour of pearlitic rail and newly developed carbide-free bainitic rail steels," Wear, vol. 408-409, no. February, pp. 151159, 2018, doi: 10.1016/j.wear.2018.05.006.

[11] K. Morton, D. F. Cannon, P. Clayton, and E. G. Jones, "The assessment of rail steels," in Rail Steels: Developments, Processing and Use, ASTM STP 644, ASTM, 1978.

[12] C. C. Viafara, M. I. Castro, J. Velez, and A. Toro, "Unlubricated sliding wear of pearlitic and bainitic steels," Wear, vol. 259, pp. 405-411, 2005, doi: 10.1016/j.wear.2005.02.013.

[13] L. C. Chang, "The rolling/sliding wear performance of high silicon carbide-free bainitic steels," Wear, vol. 258, no. 5-6, pp. 730-743, 2005, doi: 10.1016/j.wear.2004.09.064.

[14] U. P. Singh, B. Roy, S. Jha, and S. K. Bhattacharyya, "Microstructure and mechanical properties of as rolled high strength bainitic rail steels," Mater. Sci. Technol., vol. 17, no. January, pp. 33-38, 2001.

[15] H. Yokoyama, S. Mitao, S. Yamamoto, Y. Kataoka, and Toru Sugiyama, "High strength bainitic steel rails for heavy haul railways with superior damage resistance," NKK Tech. Rev., vol. 84, pp. 44-51, 2001.

[16] H. A. Aglan, Z. Y. Liu, M. F. Hassan, and M. Fateh, "Mechanical and fracture behavior of bainitic rail steel," J. Mater. Process. Technol., vol. 151, no. 1-3 SPEC. ISS., pp. 268-274, 2004, doi: 10.1016/j.jmatprotec.2004.04.073.

[17] X. Gui, K. Wang, G. Gao, R. D. K. Misra, Z. Tan, and B. Bai, "Rolling contact fatigue of bainitic rail steels: The significance of microstructure," Mater. Sci. Eng. A, vol. 657, pp. 82-85, 2016, doi: 10.1016/j.msea.2016.01.052.

[18] I. Hlavaty, M. Sigmund, K. Lucie, and P. Mohyla, "The Bainitic steels for rails applications," Mater. Eng., vol. 16, no. 4, pp. 44-50, 2009.

[19] R. Heyder and G. Girsch, "Testing of HSH rails in high-speed tracks to minimise rail damage," Wear, vol. 258, no. 7-8, pp. 1014-1021, 2005, doi: 10.1016/j.wear.2004.03.050.

[20] K. Sawley and J. Kristan, "Development of bainitic rail steels with potential resistance to rolling contact fatigue," Fatigue Fract. Eng. Mater. Struct., vol. 26, no. 10, pp. 1019-1029, 2003, doi: 10.1046/j.1460-2695.2003.00671.x.

[21] TCDD, "TCDD National High Speed Train Project 2017," 2017.

[22] Y. Li, F. Zhang, C. Chen, B. Lv, Z. Yang, and C. Zheng, "Effects of deformation on the microstructures and mechanical properties of carbide-free bainitic steel for railway crossing and its hydrogen embrittlement characteristics," Mater. Sci. Eng. A, vol. 651, pp. 945-950, 2016, doi: 10.1016/j.msea.2015.09.117.

[23] F. C. Zhang, C. L. Zheng, B. Lv, T. S. Wang, M. Li, and M. Zhang, "Effects of hydrogen on the properties of bainitic steel crossing," Eng. Fail. Anal., vol. 16, no. 5, pp. 1461-1467, 2009, doi: 10.1016/j.engfailanal.2008.09.019.

[24] M. Haddad, Y. Ivanisenko, E. Courtois-manara, and H. Fecht, "In-situ tensile test of high strength nanocrystalline bainitic steel," Mater. Sci. Eng. A, vol. 620, pp. 30-35, 2015, doi: 10.1016/j.msea.2014.09.088.

[25] P. Clayton, K. J. Sawley, P. J. Bolton, and G. M. Pell, "Wear behaviour of bainitic steels," Wear, vol. 120, no. 1987, pp. 199-220, 1987.

[26] D. Szablewski, S. Kalay, and J. Lopresti, "Development and evaluation of high performance Rail Steels for Heavy Haul Operations," in 9th World Congress on Railway Research (WCRR), 2011, pp. 1-10.

[27] TCDD, TCDD Hat Bakım El Kitabı - Üstyapı, Bölüm 1. Ankara: TCDD, 2013.

[28] EN 13674-1, "Railway applications - Track - Rail - Part 1: Vignole railway rails $46 \mathrm{~kg} / \mathrm{m}$ and above applications," 2013.

[29] M. Shahraki, C. Warnakulasooriya, and K. J. Witt, "Numerical study of transition zone between ballasted and ballastless railway track," Transp. Geotech., vol. 3, pp. 58-67, 2015, doi: 10.1016/j.trgeo.2015.05.001.

[30] A. Paixao, J. N. Varandas, E. Fortunato, and R. Calcada, "Numerical simulations to improve the use of under sleeper pads at transition zones to railway bridges," Eng. Struct., vol. 164, no. September 2017, pp. 169-182, 2018, doi: 10.1016/j.engstruct.2018.03.005. 
[31] A. Ghidini, M. Diener, A. Gianni, and J. Schneider, Innovative steel by Lucchini RS for high-speed wheel application.

[32] L. Boussalia and A. Bellaouar, "Numerical simulation of the tread defects' form impact on the eigen frequencies of a railway wheel," UPB Sci. Bull. Ser. D Mech. Eng., vol. 80, no. 2, pp. 63-74, 2018.

[33] P. Clayton and X. Su, "Surface initiated fatigue of pearlitic and bainitic steels under water lubricated rolling/sliding contact," Wear, vol. 200, no. 1-2, pp. 63-73, 1996, doi: 10.1016/S00431648(96)07250-X.

[34] J. Srivastava, P. Sarkar, and V. Ranjan, "Contact stress analysis in wheel-rail by Hertzian method and finite element method," no. October, 2014, doi: 10.1007/s40032-014-0145-x.

[35] Y. Ozdemir, "Ray-Tekerlek temasında temas parametrelerinin incelenmesi," Demiryolu Mühendisliği, no. 11, pp. 1-13, 2020.

[36] M. R. Khan and S. M. Dasaka, "Variation of effective frictional coefficient at wheel-rail contact interfaces during high speed railway operations," IOP Conf. Ser. Mater. Sci. Eng., vol. 377, no. 1, 2018, doi: 10.1088/1757-899X/377/1/012001.

[37] Y. Sarikavak, "Demiryollarında ön germeli traverslerin farklı işletme yükleri altında mekanik analizi,” Demiryolu Mühendisliği, no. 13, pp. 115-121, 2021, doi: 10.47072/demiryolu.832641.

[38] A. Paixao, C. Alves Ribeiro, N. Pinto, E. Fortunato, and R. Calcada, "On the use of under sleeper pads in transition zones at railway underpasses: experimental field testing," Structure and Infrastructure Engineering, vol. 11, no. 2. Taylor \& Francis, pp. 112-128, 2015, doi: 10.1080/15732479.2013.850730.

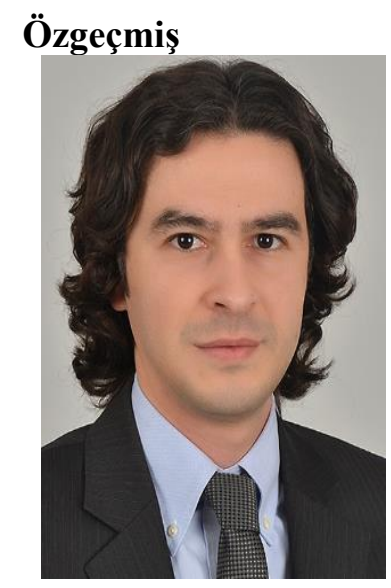

Beyanlar:

\section{Yasin SARIKAVAK}

Makine Yüksek Mühendisi, Dr.; Lisans eğitimini 2006 yılında Gazi Üniversitesi, Makine Mühendisliği Bölümü'nde tamamlamıştır. Aynı y1l TCDD, Ankara Demiryolu Fabrikası, Motor Grup Müdürlüğü’nde mühendis olarak göreve başlamıştır. Yüksek Hızlı Tren Bakım Onarım Müdürlügü̆'nde ve kurucu mühendisleri arasında yer aldığ Demiryolu Araştırma ve Teknoloji Merkezi (DATEM)'nde görev yapmıştır. Uluslararası Demiryolu Birliği (UIC), Japon Uluslararası İşbirliği Ajansı (JICA) gibi kurumlarda çeşitli komisyonlarda görev almıştır. Halen Ankara Yıldırım Beyazıt Üniversitesi, Makine Mühendisliği Bölümü’nde öğretim üyesi olarak görev yapmaktadır. E-Posta: sarikavak@gmail.com; ysarikavak@ybu.edu.tr

Bu makalede bilimsel araştırma ve yayın etiğine uyulmuştur.

Tüm yazarların eşit oranda katkısı olmuştur. 